Article

\title{
Kinetics of Ultrasound-Assisted Flavonoid Extraction from Agri-Food Solid Wastes Using Water/Glycerol Mixtures
}

\author{
Dimitris P. Makris \\ Department of Food Science \& Nutrition, School of Environment, University of the Aegean, Myrina, \\ Lemnos 81400, Greece; dmakris@aegean.gr; Tel.: +30-22540-83114 \\ Academic Editor: Filippo Sgroi \\ Received: 26 November 2015; Accepted: 18 January 2016; Published: 26 January 2016
}

\begin{abstract}
Red grape pomace (RGP) and onion solid wastes (OSW) were used as raw material to produce flavonoid-enriched extracts, using ultrasound-assisted solid-liquid extraction. The extraction medium used was composed of water and glycerol and under the conditions used the extraction of flavonoids from both materials was shown to obey first-order kinetics. Maximum diffusivities $\left(D_{\mathrm{e}}\right)$ values were $4.01 \times 10^{-11}$ and $2.35 \times 10^{-11} \mathrm{~m}^{2} \cdot \mathrm{s}^{-1}$, for RGP and OSW extraction, respectively, while the corresponding activation energies $\left(E_{\mathrm{a}}\right)$ were 14.00 and $15.23 \mathrm{~kJ} \cdot \mathrm{mol}^{-1}$.
\end{abstract}

Keywords: extraction kinetics; flavonoids; glycerol; onion solid wastes; red grape pomace

\section{Introduction}

In spite of the variety of phytochemicals that may be encountered in agri-food by-products and wastes, significant attention has been given to polyphenols. This particular family of secondary metabolites includes an enormous number of compounds with diverse structures and bioactivities, including antioxidant, anti-inflammatory and anti-cancer properties [1,2]. Hence, there is an on-going research pertaining to the effective recovery of such substances, with the aim of utilizing them in food, pharmaceuticals and cosmetics [3,4].

The valorization of waste biomass for the recovery of polyphenolic compounds should include processes that generate far less or even zero further waste; otherwise no concept of "green" or "sustainable" could be substantiated. Thus, research on such a field should focus on the discovery and design of extraction processes, which will allow the use of alternative solvents and renewable natural products, and ensure a safe and high quality extract/product [5]. This challenge strongly suggests that technological innovations in the direction of utilizing novel extraction media and techniques are imminent.

The recovery of polyphenolic compounds from plant food industry wastes is currently a major concept towards the development of efficient techniques and a much research has been focused on efficient methodologies dealing with solid-liquid extraction. The utilization of a suitable solvent in combination with treatments, such as microwave heating, ultrasounds and high pressure (pressurized liquids), have become the state-of-the-art, displaying high recovery yields [6]. On the other hand, several extraction processes developed on a laboratory scale are characterized by significant shortcomings and the prospect of industrial implementation is rather particularly limited. This is owed to the toxicity of solvents frequently used and the need for recycling (acetone, methanol), strict control by State laws (ethanol), as well as increased cost and questionable efficiency (pressurized liquids, supercritical fluids) [5].

Glycerol is a material that has not been extensively used for extraction purposes, despite the fact that it possesses attractive characteristics, such as lack of toxicity, lack of flammability, volatility and 
reactivity, as well as low cost, as it is a biodiesel industry by-product. Previous studies demonstrated that water/glycerol mixtures may be very effective in extracting polyphenols $[7,8]$, but the information available to date is rather poor to fully evaluate glycerol's potency for efficient polyphenol recovery from plant material. Such an evaluation would embrace kinetic studies [9], to ascertain the efficacy and rapidity of extraction, carried out with a given solvent system. With regard to water/glycerol mixtures, polyphenol extraction has been shown in some instances to follow second-order kinetics [10,11], yet results from the extraction of various plant materials demonstrated that polyphenol extraction may follow first-order kinetics as well [12,13]. Furthermore, the ultrasound-assisted extraction of either red grape pomace (RGP) or onion solid wastes (OSW) was never been previously reported and thus no data are available in the relevant literature. Hence a kinetic examination becomes imminent in order to generate detailed data, which could be used for comparison of the efficiency of various extraction methodologies and for the engineering of improved extraction processes.

To this purpose, this study was performed to examine the kinetics of ultrasound-assisted flavonoid extraction from two agri-food residues, red grape pomace and onion solid wastes. Both solid wastes contain mainly flavonoid compounds, and the test employed to assess the total flavonoid yield is very specific, as opposed to the widely used Folin-Ciocalteu for total polyphenol determination, which determines the totality of polyphenols and not only flavonoids. Thus the data provided allowed for a more accurate and reliable determination of the extraction kinetics.

\section{Results and Discussion}

To identify the model that better described flavonoid extraction from both RGP and OSW, $\mathrm{Y}_{\text {TFn }}$ values were plotted as a function of $t$ (Figures 1 and 2). The model best fitted to the extraction kinetics using non-linear regression was a 2-parameter, single exponential rise-to-maximum, described by the equation:

$$
y=\mathrm{a}\left(1-e^{-\mathrm{bx}}\right)
$$

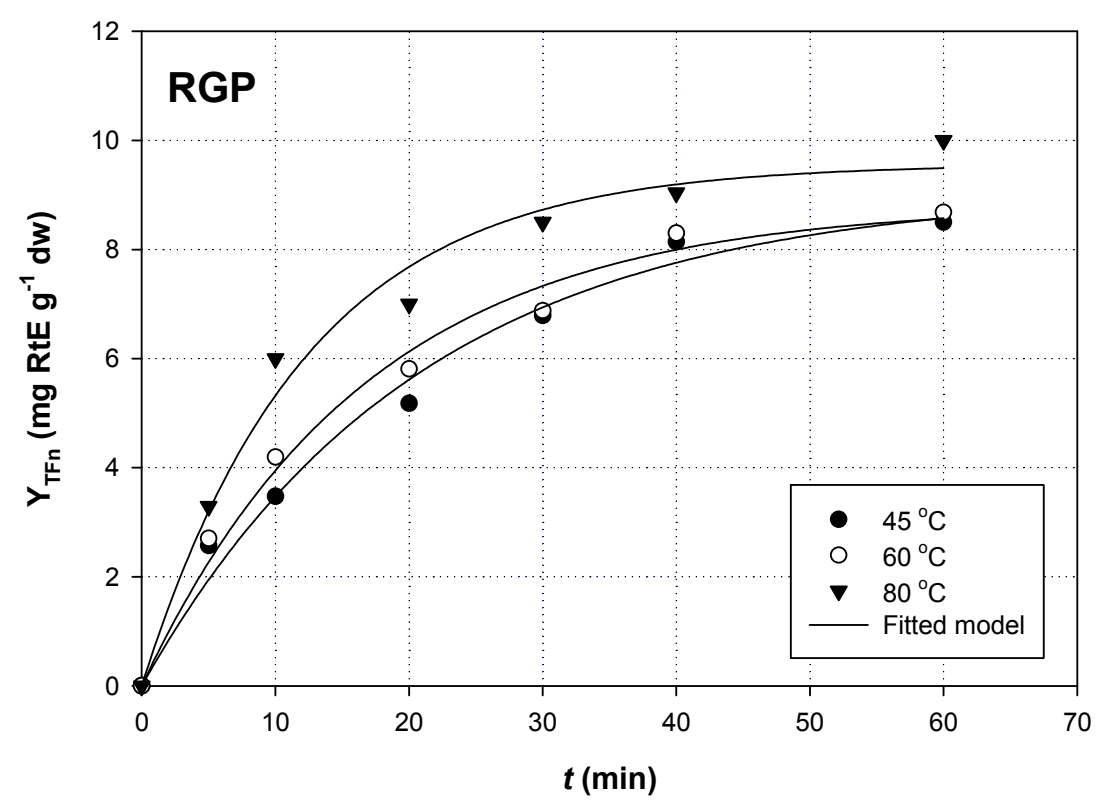

Figure 1. Non-linear regression between $Y_{\mathrm{TFn}}$ and $t$ values during extraction of $\mathrm{RGP} ; \mathrm{R}_{\mathrm{L} / \mathrm{S}}=90 \mathrm{~mL} \cdot \mathrm{g}^{-1}$ and $C_{\mathrm{gl}}=90 \%(w / v)$. Extractions were carried out under sonication $\left(140 \mathrm{~W}, 37 \mathrm{kHz}, 35 \mathrm{~W} \cdot \mathrm{L}^{-1}\right)$. 


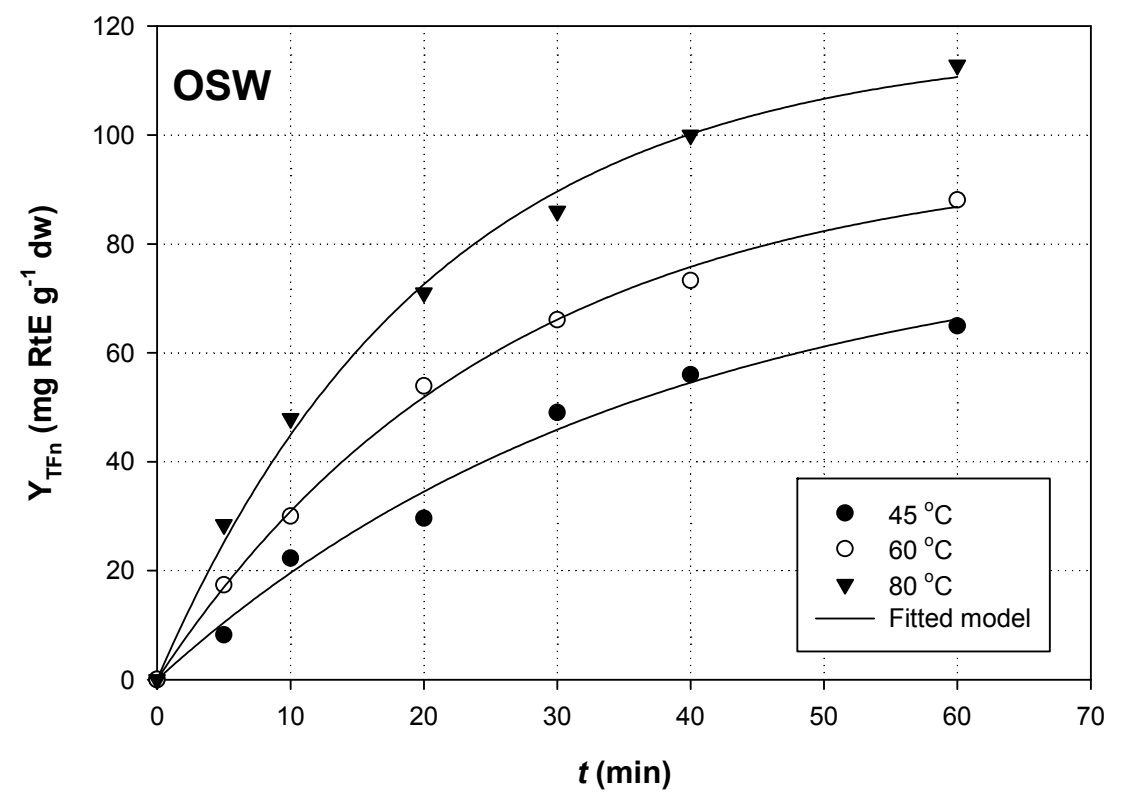

Figure 2. Non-linear regression between $\mathrm{Y}_{\mathrm{TFn}}$ and $t$ values during extraction of $\mathrm{OSW} ; \mathrm{R}_{\mathrm{L} / \mathrm{S}}=90 \mathrm{~mL} \cdot \mathrm{g}^{-1}$ and $C_{\mathrm{gl}}=90 \%(w / v)$. Extractions were carried out under sonication $\left(140 \mathrm{~W}, 37 \mathrm{kHz}, 35 \mathrm{~W} \cdot \mathrm{L}^{-1}\right)$.

For both RGP and OSW extractions, and for all temperatures tested, correlation was high and statistically significant $\left(\mathrm{R}^{2}>0.98, p<0.0001\right)$. This suggested that extraction yield for total flavonoids as a function of $t$ can be adequately predicted by the Equation (1), which represents first-order kinetics, considering the boundary conditions $t=0$ to $t$ and $\mathrm{Y}_{\mathrm{TFn}(t)}=0$ to $\mathrm{Y}_{\mathrm{TFn}(t)}$ :

$$
\mathrm{Y}_{\mathrm{TFn}(t)}=\mathrm{Y}_{\mathrm{TFn}(s)}\left(1-e^{-k t}\right)
$$

The above considerations regarding diffusion were admitted, assuming that:

1. Flavonoids were uniformly distributed within the solid particles.

2. The particles were considered to be spherical.

3. Diffusivity remained constant throughout the extraction process.

4. The solution was perfectly mixed upon the energy dissipated by the ultrasonic waves.

5. Resistance to mass transfer was negligible in the liquid phase.

6. The transport of flavonoids from the solid particles into the liquid phase occurred through diffusion.

where $\mathrm{Y}_{\mathrm{TFn}(t)}$ is the extraction yield at any time $t ; \mathrm{Y}_{\mathrm{TFn}(s)}$ the extraction yield at saturation (equilibrium); and $k$ the apparent first-order extraction rate constant. Both $\mathrm{Y}_{\operatorname{TFn}(s)}$ and $k$ values were calculated by non-linear regression, using SigmaPlot ${ }^{\mathrm{TM}} 12.0$ [14].

Rearrangement of Equation (2) would give:

$$
\begin{gathered}
\ln \left(\frac{Y_{\mathrm{TFn}(s)}}{Y_{\mathrm{TFn}(s)}-Y_{\mathrm{TFn}(t)}}\right)=k t \\
\log \left(\mathrm{Y}_{\mathrm{TFn}(s)}-\mathrm{Y}_{\mathrm{TFn}(t)}\right)=\log \left(\mathrm{Y}_{\mathrm{TFn}(s)}\right)-\frac{k}{2.303} t
\end{gathered}
$$

A plot of $\log \left(\mathrm{Y}_{\mathrm{TFn}(s)}-\mathrm{Y}_{\mathrm{TFn}(t)}\right)$ as a function of $t$ would yield a straight line with slope $=-k$ (Figures 3 and 4). 


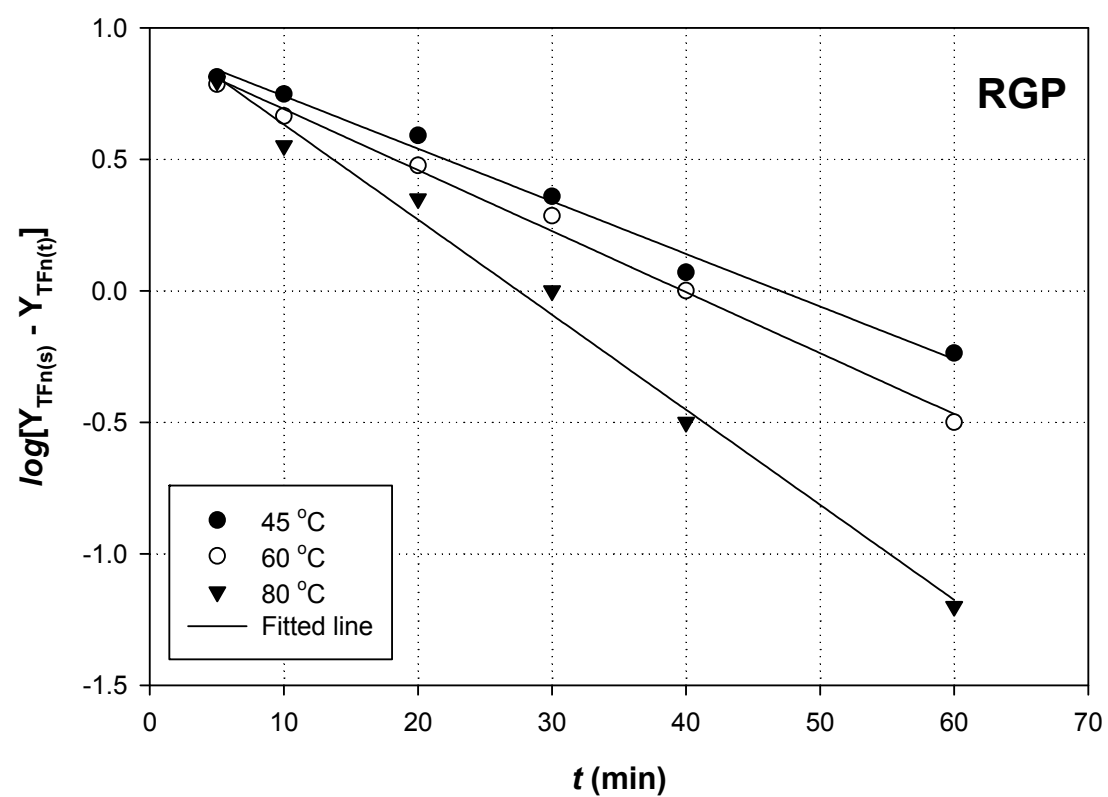

Figure 3. First-order kinetics of flavonoid extraction from RGP, using $90 \%(w / v)$ glycerol. Extractions were carried out with $\mathrm{R}_{\mathrm{L} / \mathrm{S}}=90 \mathrm{~mL} \cdot \mathrm{g}^{-1}$ and $C_{\mathrm{gl}}=90 \%(w / v)$, under sonication $(140 \mathrm{~W}, 37 \mathrm{kHz}$, $\left.35 \mathrm{~W} \cdot \mathrm{L}^{-1}\right)$.

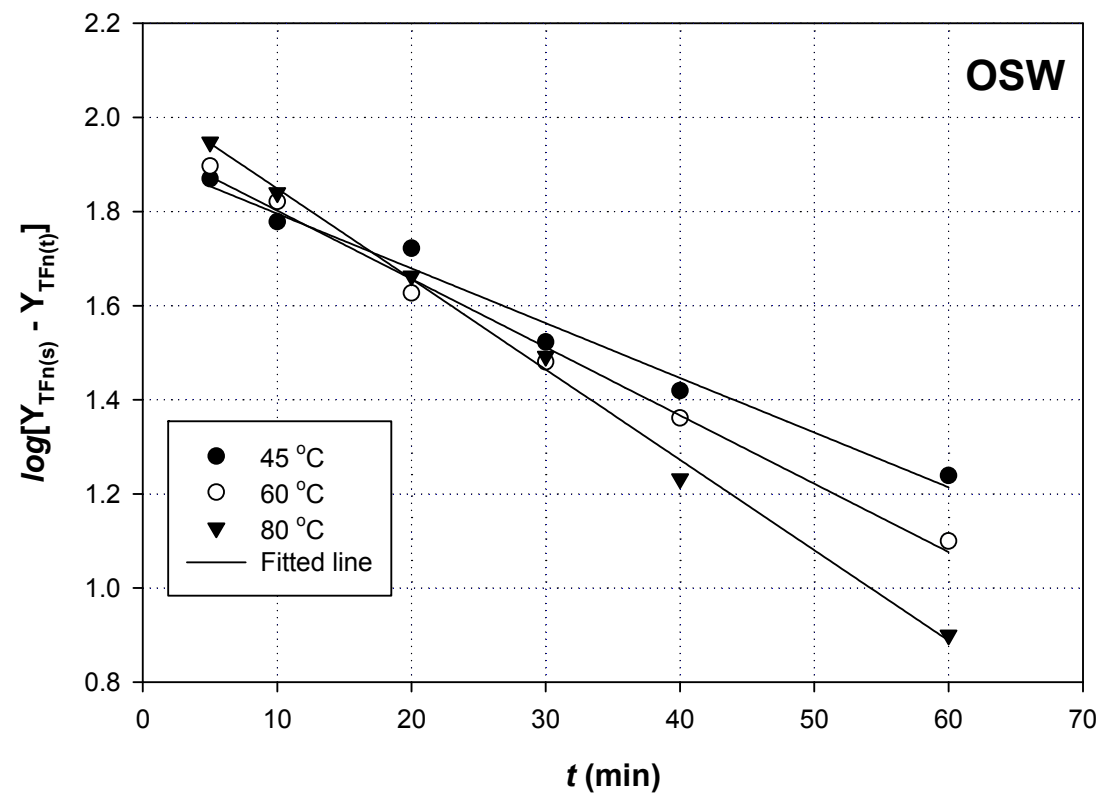

Figure 4. First-order kinetics of flavonoid extraction from OSW, using $90 \%(w / v)$ glycerol. Extractions were carried out with $\mathrm{R}_{\mathrm{L} / \mathrm{S}}=90 \mathrm{~mL} \cdot \mathrm{g}^{-1}$ and $C_{\mathrm{gl}}=90 \%(w / v)$, under sonication $(140 \mathrm{~W}, 37 \mathrm{kHz}$, $\left.35 \mathrm{~W} \cdot \mathrm{L}^{-1}\right)$.

Based on Fick's second law, the mathematical expression that links $Y$ and the effective diffusion of the solute (polyphenols/pigments) can be described as follows [15]:

$$
\frac{Y_{T F n(t)}}{Y_{T F n(s)}}=1-\frac{6}{\pi^{2}} \sum_{n=1}^{\infty} \frac{1}{n} e^{-\frac{D_{e} n^{2} \pi^{2} t}{r^{2}}}
$$


where $D_{\mathrm{e}}$ is the diffusivity $\left(\mathrm{m}^{2} \cdot \mathrm{s}^{-1}\right)$; and $r$ the radius of the solid particles $(\mathrm{m})$. However, after the elapse of a short extraction period, only the first term of the series solution is considered significant, hence Equation (5) can be written as:

$$
1-\frac{Y_{T F n(t)}}{Y_{T F n(s)}}=\frac{6}{\pi^{2}} e^{-\frac{D_{e} \pi^{2} t}{r^{2}}}
$$

The linearized form of Equation (6) would be:

$$
\ln \left(\frac{Y_{T F n(s)}}{Y_{T F n(s)}-Y_{T F n(t)}}\right)=\ln \frac{\pi^{2}}{6}+\frac{D_{e} \pi^{2} t}{r^{2}}
$$

The $D_{\mathrm{e}}$ coefficient can then be calculated graphically from the slop of the straight line, obtained after plotting $\ln \left(\frac{Y_{T F n(s)}}{Y_{T F n(s)}-Y_{T F n(t)}}\right)$ against $t$.

The kinetic parameters deriving from engineering the extraction process for both RGP and OSW were determined and analytically presented in Table 1 . Raising the temperature from 50 to $80{ }^{\circ} \mathrm{C}$ had a positive effect on $\mathrm{Y}_{\mathrm{TFn}(\mathrm{s})}$ for the extraction from both materials, although for RGP a slight decrease was recorded by increasing temperature from 45 to $60^{\circ} \mathrm{C}$. The effect of temperature on the extraction of RGP in several instances is positive [16,17], since higher temperatures facilitate both polyphenol diffusion and increase solubility in polar solvents [18,19]. By contrast, total polyphenol extraction from OSW has been shown to decline at temperatures higher than $40{ }^{\circ} \mathrm{C}$ [20]. Furthermore, it has been demonstrated that solubilization of catechin, an abundant RGP constituent, is endothermic and, thus, thermodynamically favored at higher temperatures [21]. Similar phenomena may hold true for other RGP constituents too. On the other hand, temperature cannot be increased beyond certain limits, as this has been proven detrimental to anthocyanins, inducing their thermal degradation $[22,23]$.

Table 1. Kinetic parameters determined for the $\mathrm{Y}_{\mathrm{TFn}}$ at the temperatures tested, using first-order kinetic model. All extractions were performed with $90 \%(w / v)$ glycerol at a $\mathrm{R}_{\mathrm{L} / \mathrm{S}}$ of $90 \mathrm{~mL} \cdot \mathrm{g}^{-1}$, under

\begin{tabular}{|c|c|c|c|c|}
\hline \multicolumn{5}{|c|}{ Kinetic Parameters } \\
\hline $\mathrm{T}\left({ }^{\circ} \mathrm{C}\right)$ & $\mathbf{k}\left(\min ^{-1}\right)$ & $\mathrm{Y}_{\mathrm{TFn}(\mathrm{s})}\left(\mathrm{mg}\right.$ RtE$\left.\cdot \mathrm{g}^{-1} \mathrm{dw}\right)$ & $\mathrm{D}_{\mathrm{e}}\left(\mathrm{m}^{\mathbf{2}} \cdot \mathrm{s}^{-1}\right) \times \mathbf{1 0}^{-11}$ & $\mathrm{E}_{\mathrm{a}}\left(\mathrm{kJ} \cdot \mathrm{mol}^{-1}\right)$ \\
\hline \multicolumn{5}{|l|}{ RGP } \\
\hline 45 & 0.0482 & 9.08 & 0.17 & \multirow{3}{*}{14.00} \\
\hline 60 & 0.0594 & 8.82 & 2.69 & \\
\hline 80 & 0.0813 & 9.57 & 4.01 & \\
\hline \multicolumn{5}{|l|}{ OSW } \\
\hline 45 & 0.0272 & 82.30 & 1.11 & \multirow{3}{*}{15.23} \\
\hline 60 & 0.0387 & 96.28 & 1.74 & \\
\hline 80 & 0.0484 & 117.06 & 2.35 & \\
\hline
\end{tabular}
sonication $\left(140 \mathrm{~W}, 37 \mathrm{kHz}, 35 \mathrm{~W} \cdot \mathrm{L}^{-1}\right)$.

The maximum $\mathrm{Y}_{\mathrm{TFn}(\mathrm{s})}$, achieved at $80{ }^{\circ} \mathrm{C}$, was $9.57 \mathrm{mg} \mathrm{RtE} \cdot \mathrm{g}^{-1} \mathrm{dw}$ for RGP and $117.06 \mathrm{RtE} \cdot \mathrm{g}^{-1}$ $\mathrm{dw}$ for OSW. Regarding the kinetics of TFn extraction, $k$ was found to increase in response to raising the temperature, reaching 0.0813 and $0.484 \mathrm{~min}^{-1}$ at $80{ }^{\circ} \mathrm{C}$, for RGP and OSW, respectively. These values are lower than $0.130 \mathrm{~min}^{-1}$ reported for polyphenol extraction from grape juice bagasse using $50 \%$ ethanol [12] and $0.088 \mathrm{~min}^{-1}$ reported for UAE (ultrasound-assisted extraction) of polyphenols from apple peels at $40^{\circ} \mathrm{C}$ using water [13], but higher than $0.012 \mathrm{~min}^{-1}$ found for water extraction of Tilia sapwood polyphenols at $80^{\circ} \mathrm{C}$ [9]. Furthermore, the outcome from previous studies on the extraction 
of anthocyanins from RGP with $50 \%$ ethanol yielded $k$ values between 0.034 and $0.157 \mathrm{~min}^{-1}$, within a temperature range of $25-60^{\circ} \mathrm{C}$ [24].

In order to obtain quantitative data pertaining to the effect of temperature on the extraction rate, the Arrhenius equation was used:

$$
k=k_{0} e^{-\frac{E_{a}}{R T}}
$$

where $k_{0}$ is the temperature-independent factor $\left(\min ^{-1}\right) ; R$ the universal gas constant $\left(8.314 \mathrm{~J} \cdot \mathrm{K}^{-1} \cdot \mathrm{mol}^{-1}\right) ; T$ the absolute temperature $(\mathrm{K})$; and $E_{\mathrm{a}}$ the activation energy $\left(\mathrm{J} \cdot \mathrm{mol}^{-1}\right)$. Transformation of Equation (8) allows obtaining a linear relationship between the first-order extraction rate constant and the inverse of $T$ :

$$
\ln k=\ln k_{0}+\left(-\frac{E_{a}}{R}\right) \frac{1}{T}
$$

Therefore, $E_{\mathrm{a}}$ could be determined graphically, since the straight line obtained by plotting $\ln k$ as a function of $1 / T$ would have a slope $=-\frac{E_{a}}{R}$ (Figure 5).

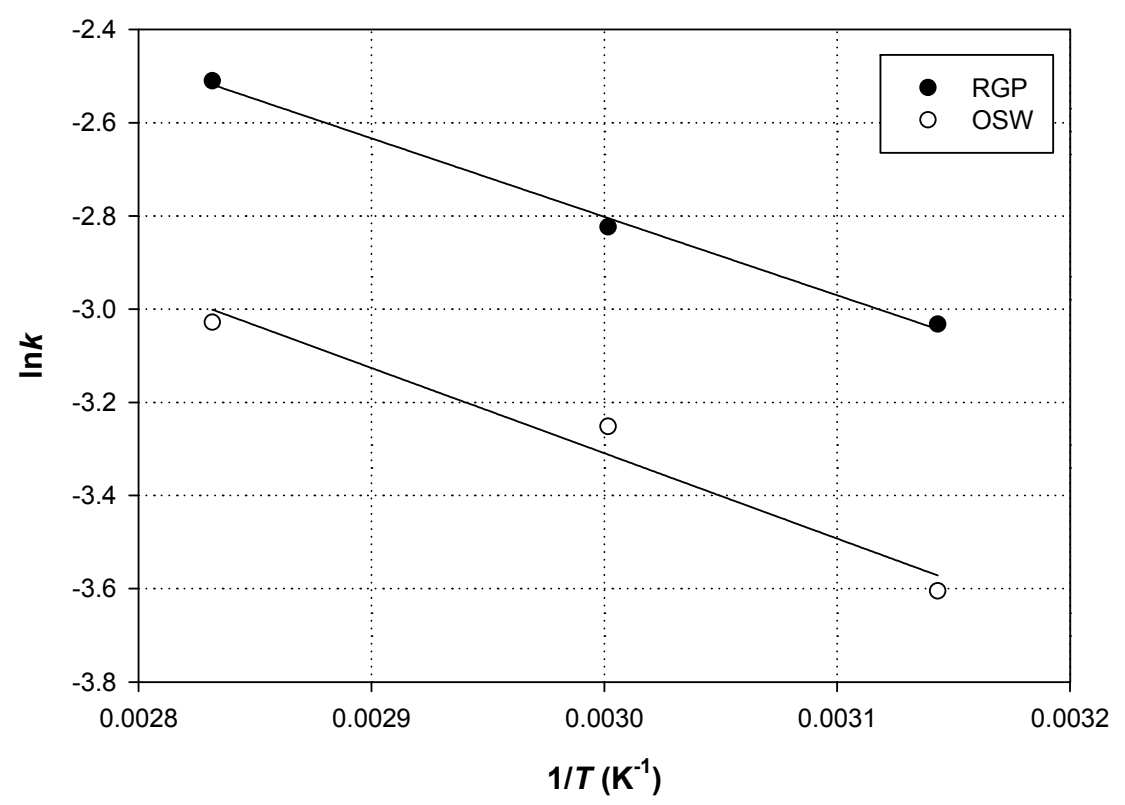

Figure 5. Relationships between temperature and the first-order extraction rate constant, $\ln k$, for extraction of flavonoids from RGP and OSW. Extractions were carried out with $\mathrm{R}_{\mathrm{L} / \mathrm{S}}=90 \mathrm{~mL} \cdot \mathrm{g}^{-1}$ and $C_{\mathrm{gl}}=90 \%(w / v)$, under sonication $\left(140 \mathrm{~W}, 37 \mathrm{kHz}, 35 \mathrm{~W} \cdot \mathrm{L}^{-1}\right)$.

The $E_{\mathrm{a}}$ determined for TFn extraction for RGP and OSW were 14.00 and $15.23 \mathrm{~kJ} \cdot \mathrm{mol}^{-1}$, respectively. These values are almost 3-3.5 times higher than $4.6 \mathrm{~kJ} \cdot \mathrm{mol}^{-1}$, determined for the UAE of TP (total polyphenols) from RGP [25], employing 50\% ethanol and almost 2.2 times higher than $6.34 \mathrm{~kJ} \cdot \mathrm{mol}^{-1}$ found for the UAE of orange peel polyphenols with $75 \%$ ethanol [26]. It should be emphasized that $E_{\mathrm{a}}$ determined for the extraction of polyphenols from various plant sources varied from $0.5 \mathrm{~kJ} \cdot \mathrm{mol}^{-1}$ [18] to as high as $97.1 \mathrm{~kJ} \cdot \mathrm{mol}^{-1}$ [27], depending on the solvent system and the conditions used. In general, the sufficient amount of $E_{\mathrm{a}}$ for polyphenol extraction lies from 14.54 [28] to $56.00 \mathrm{~kJ} \cdot \mathrm{mol}^{-1}$ [15].

In both cases $E_{\mathrm{a}}$ were positive, which is in agreement with endothermic process. $E_{\mathrm{a}}$ may be associated with both medium and matrix resistance, which the solute should overcome. If $E_{\mathrm{a}}<20 \mathrm{~kJ} \cdot \mathrm{mol}^{-1}$, then extraction is managed by diffusion [25]. Ultrasounds can assist with extraction processes both through cell disruption and by enhancing mass transfer in the boundary layer surrounding the solid matrix [29]. The relatively low $E_{\mathrm{a}}$ levels found for both extractions of RGP 
and OSW indicated that ultrasonication is an effective means of assisting extraction, by providing the appropriate energy dissipation for efficient mass transfer. The ultrasonic energy is thought to accelerate the diffusional process by enhancing the solid particle permeability by the solvent, hence facilitating polyphenol release [30]. It could also be argued that the lower energy barrier required to initiate diffusion is provided by ultrasonic energy, which may contribute in overcoming solute-solute and solute-matrix interactions, thus decreasing $E_{\mathrm{a}}$ of the extraction process.

To support this hypothesis, the diffusivity $\left(D_{\mathrm{e}}\right)$ for both extractions were also calculated (Table 1$)$. As can be seen, flavonoid extraction from RGP and OSW attained a $D_{\mathrm{e}}$ level of $4.01 \times 10^{-11} \mathrm{~m}^{2} \cdot \mathrm{s}^{-1}$ and $2.35 \times 10^{-11} \mathrm{~m}^{2} \cdot \mathrm{s}^{-1}$ at $80^{\circ} \mathrm{C}$, respectively, which are higher than $0.14 \times 10^{-12}$ to $1.57 \times 10^{-12} \mathrm{~m}^{2} \cdot \mathrm{s}^{-1}$ reported for extraction of lignans from flaxseed [15] and $1.05 \times 10^{-12} \mathrm{~m}^{2} \cdot \mathrm{s}^{-1}$ for polyphenols extraction from RGP with $50 \%$ ethanol [31] and $12.3 \times 10^{-12}$ to $15.0 \times 10^{-12} \mathrm{~m}^{2} \cdot \mathrm{s}^{-1}$ achieved in the extraction of polyphenols from RGP using $60 \%$ ethanol [32]. $D_{\mathrm{e}}$ as high as $12.3 \times 10^{-11} \mathrm{~m}^{2} \cdot \mathrm{s}^{-1}$ and $1.2 \times 10^{-11}$ to $25.0 \times 10^{-11} \mathrm{~m}^{2} \cdot \mathrm{s}^{-1}$ were also determined for polyphenol and anthocyanin extraction from milled berries with $67 \%$ ethanol, respectively [33].

\section{Experimental Section}

\subsection{Chemicals and Reagents}

Rutin (quercetin 3-O-rutinoside) was from Sigma Chemical Co. (St. Louis, MO, USA). Aluminium chloride $\left(\mathrm{AlCl}_{3}\right)$ was from Merck (Darmstad, Germany). Glycerol was obtained from Fisher Scientific (Pittsburgh, PA, USA).

\subsection{Agri-Food Wastes}

Red-skinned onions, with no apparent damages and infections, were purchased from a local grocery store (Myrina, Lemnos, Greece). The bulbs were transferred to the laboratory and peeled immediately using a sharp cutter, so as to remove the outer dry and semi-dry layers, as well as the apical trims (onion solid wastes-OSW). Red grape pomace (RGP) originating from vinification of Agiorgitiko variety (Vitis vinifera spp.) was kindly provided by the Department of Food Science and Human Nutrition, Agricultural University of Athens. The materials were placed in an oven set at $65^{\circ} \mathrm{C}$ for $48 \mathrm{~h}$ and then pulverized to a fine powder in a laboratory mill (approximate mean particle size $0.3 \mathrm{~mm}$ for RGP and $1 \mathrm{~mm}$ for OSW). The pulverized material was kept at $-20{ }^{\circ} \mathrm{C}$ until used. This powder was used for all extraction processes.

\subsection{Ultrasound-Assisted Extraction}

A previous methodology was employed [34], with slight modifications. Extractions were carried out in plastic containers, using $100 \mathrm{~mL}$ of $90 \%(w / v)$ aqueous glycerol and an amount of pulverized material to provide a liquid-to-solid ratio $\left(\mathrm{R}_{\mathrm{L} / \mathrm{S}}\right)$ of $90 \mathrm{~mL} \cdot \mathrm{g}^{-1}$. The mixture was vortexed for a few seconds to form slurry and ultrasound-assisted extractions were performed in a temperature-controlled, sonication bath (Elma P70, Singer, Germany), at a fixed power of $140 \mathrm{~W}$, a frequency of $37 \mathrm{kHz}$, and an acoustic energy density (AED) of $35 \mathrm{~W} \cdot \mathrm{L}^{-1}$, for $60 \mathrm{~min}$, at 45,60 and $80^{\circ} \mathrm{C}$. Sampling was accomplished at predetermined intervals. Samples were placed in $1.5 \mathrm{~mL}$ Eppendorf tubes (Hamburg, Germany) and centrifuged in a table centrifugator (Hermle, Wehingen, Germany) at 10,000 rpm for $10 \mathrm{~min}$. The clear solution was used for further analysis.

\subsection{Determination of Total Flavonoid Yield $\left(Y_{T F n}\right)$}

A previously published protocol was used [35], with modifications. An aliquot of $0.25 \mathrm{~mL}$ sample was mixed with $0.75 \mathrm{~mL} \mathrm{AlCl}_{3}$ reagent $\left(0.16 \%(w / v) \mathrm{AlCl}_{3}\right.$ in $5 \%(v / v)$ acetic acid in methanol) and allowed to stand for $30 \mathrm{~min}$, at room temperature. The absorbance was obtained at $415 \mathrm{~nm}\left(\mathrm{~A}_{415}\right)$ and the total flavonoid concentration $\left(C_{\mathrm{TFn}}\right)$ was calculated from a calibration curve, constructed with rutin 
(quercetin 3-O-rutinoside) as the calibration standard. Yield in total flavonoids $\left(\mathrm{Y}_{\mathrm{TFn}}\right)$, expressed as $\mathrm{mg}$ rutin equivalents (RtE) per g of dry weight, was determined using Equation (10):

$$
Y_{T F n}\left(m g R t E g^{-1} d w\right)=\frac{C_{T F n} \times V}{m}
$$

where $V$ is the volume of the extraction medium (L); and $m$ the dry weight of the plant material (g).

\subsection{Kinetics and Statistical Analyses}

All determinations were carried out at least in triplicate and values were averaged and given along the standard deviation ( \pm S.D.). Kinetics was performed by carrying out non-linear regression between $\mathrm{Y}_{\mathrm{TFn}}$ and $t$ values. Kinetics and linear and non-linear correlations were established at least at a 95\% significance level $(p<0.05)$. For all statistics, SigmaPlot ${ }^{\mathrm{TM}} 12.0$ and Microsoft Excel ${ }^{\mathrm{TM}} 2010$ were used.

\section{Conclusions}

This examination provided for the first time concrete evidence that a solvent system composed of $90 \%(w / v)$ aqueous glycerol can efficiently extract flavonoids from RGP and OSW, with the assistance of ultrasonication. In both cases, extraction yield increased in response to raising the temperature up to $80^{\circ} \mathrm{C}$, a phenomenon ascribed to higher diffusion. The relatively low activation energies for the extraction of flavonoids were attributed to the effect of ultrasounds, which were assumed to provide the appropriate dissipation energy for such a process. The satisfactory extraction yields achieved, confirmed such a hypothesis. This is a significant outcome, considering that glycerol is an inexpensive, abundant and non-toxic bio-material. Hence the adoption of similar methodologies by the industry would be anticipated to form the basis for the development of green processes, aimed at the valorization of food industry waste streams and the sustainable production of value-added commodities, such as food additives, food supplements, pharmaceutical formulations, and cosmetics.

Acknowledgments: Despena Trasanidou, Photene Katsampa and Evdokea Valsamedou are thanked for assisting laboratory experiments.

Conflicts of Interest: The author declare no conflict of interest.

\section{Nomenclature}

$\begin{array}{ll}\text { AED } & \text { acoustic energy density }\left(\mathrm{W} \cdot \mathrm{L}^{-1}\right) \\ C_{\mathrm{TFn}} & \text { total flavonoid concentration }\left(\mathrm{mg} \mathrm{RtE} \cdot \mathrm{L}^{-1}\right) \\ D_{\mathrm{e}} & \text { diffusivity }\left(\mathrm{m}^{2} \cdot \mathrm{s}^{-1}\right) \\ E_{\mathrm{a}} & \text { activation energy }\left(\mathrm{kJ} \cdot \mathrm{mol}^{-1}\right) \\ k & \text { first-order extraction rate constant }\left(\mathrm{min}^{-1}\right) \\ \mathrm{R}_{\mathrm{L} / \mathrm{S}} & \text { liquid-to-solid ratio }\left(\mathrm{mL} \cdot \mathrm{g}^{-1}\right) \\ t & \text { time (min) } \\ T & \text { temperature }\left({ }^{\circ} \mathrm{C} \text { or } \mathrm{K}\right) \\ \mathrm{Y}_{\mathrm{TFn}} & \text { yield in total flavonoids }\left(\mathrm{mg} \mathrm{RtE} \cdot \mathrm{g}^{-1}\right) \\ \mathrm{Y}_{\mathrm{TFn}(\mathrm{s})} & \text { yield in total flavonoids at saturation }\left(\mathrm{mg} \mathrm{RtE} \cdot \mathrm{g}^{-1}\right)\end{array}$

\section{References}

1. Dai, J.; Mumper, R.J. Plant phenolics: Extraction, analysis and their antioxidant and anticancer properties. Molecules 2010, 15, 7313-7352. [CrossRef] [PubMed]

2. Đilas, S.; Čanadanović-Brunet, J.; Ćetković, G. By-products of fruits processing as a source of phytochemicals. Chem. Ind. Chem. Eng. Q. 2009, 15, 191-202. [CrossRef] 
3. Koutinas, A.A.; Vlysidis, A.; Pleissner, D.; Kopsahelis, N.; Lopez Garcia, I.; Kookos, I.K.; Papanikolaou, S.; Kwan, T.H.; Lin, C.S.K. Valorization of industrial waste and by-product streams via fermentation for the production of chemicals and biopolymers. Chem. Soc. Rev. 2014, 43, 2587-2627. [CrossRef] [PubMed]

4. Liguori, R.; Amore, A.; Faraco, V. Waste valorization by biotechnological conversion into added value products. Appl. Microbiol. Biotechnol. 2013, 97, 6129-6147. [CrossRef] [PubMed]

5. Chemat, F.; Vian, M.A.; Cravotto, G. Green extraction of natural products: Concept and principles. Int. J. Mol. Sci. 2012, 13, 8615-8627. [CrossRef] [PubMed]

6. Baiano, A. Recovery of biomolecules from food wastes-A review. Molecules 2014, 19, 14821-14842. [CrossRef] [PubMed]

7. Apostolakis, A.; Grigorakis, S.; Makris, D.P. Optimisation and comparative kinetics study of polyphenol extraction from olive leaves (Olea europaea) using heated water/glycerol mixtures. Sep. Purif. Technol. 2014, 128, 89-95. [CrossRef]

8. Karakashov, B.; Grigorakis, S.; Loupassaki, S.; Makris, D.P. Optimisation of polyphenol extraction from Hypericum perforatum using aqueous glycerol and response surface methodology. J. Appl. Res. Med. Aromat. Plants 2015, 2, 1-8. [CrossRef]

9. Harouna-Oumarou, H.A.; Fauduet, H.; Porte, C.; Ho, Y.-S. Comparison of kinetic models for the aqueous solid-liquid extraction of Tilia sapwood in a continuous stirred tank reactor. Chem. Eng. Commun. 2007, 194, 537-552. [CrossRef]

10. Karakashov, B.; Grigorakis, S.; Loupassaki, S.; Mourtzinos, I.; Makris, D.P. Optimisation of organic solvent-free polyphenol extraction from Hypericum triquetrifolium turra using box-behnken experimental design and kinetics. Int. J. Ind. Chem. 2015, 6, 85-92. [CrossRef]

11. Michail, A.; Sigala, P.; Grigorakis, S.; Makris, D.P. Optimisation of ultrasound-assisted polyphenol extraction from spent filter coffee using aqueous glycerol. Chem. Eng. Commun. 2016, 203, 407-413. [CrossRef]

12. Sant'Anna, V.; Brandelli, A.; Marczak, L.D.F.; Tessaro, I.C. Kinetic modeling of total polyphenol extraction from grape marc and characterization of the extracts. Sep. Purif. Technol. 2012, 100, 82-87. [CrossRef]

13. Pingret, D.; Fabiano-Tixier, A.-S.; Le Bourvellec, C.; Renard, C.M.; Chemat, F. Lab and pilot-scale ultrasound-assisted water extraction of polyphenols from apple pomace. J. Food Eng. 2012, 111, 73-81. [CrossRef]

14. SigmaPlot ${ }^{\mathrm{TM}}$, Version 12.0. Systat Software Inc.: San Jose, CA, USA.

15. Ho, C.H.; Cacace, J.E.; Mazza, G. Mass transfer during pressurized low polarity water extraction of lignans from flaxseed meal. J. Food Eng. 2008, 89, 64-71. [CrossRef]

16. Aliakbarian, B.; Fathi, A.; Perego, P.; Dehghani, F. Extraction of antioxidants from winery wastes using subcritical water. J. Supercrit. Fluids 2012, 65, 18-24. [CrossRef]

17. Brahim, M.; Gambier, F.; Brosse, N. Optimization of polyphenols extraction from grape residues in water medium. Ind. Crops Prod. 2014, 52, 18-22. [CrossRef]

18. Boussetta, N.; Vorobiev, E.; Deloison, V.; Pochez, F.; Falcimaigne-Cordin, A.; Lanoisellé, J.-L. Valorisation of grape pomace by the extraction of phenolic antioxidants: Application of high voltage electrical discharges. Food Chem. 2011, 128, 364-370. [CrossRef]

19. Galanakis, C.; Goulas, V.; Tsakona, S.; Manganaris, G.; Gekas, V. A knowledge base for the recovery of natural phenols with different solvents. Int. J. Food Prop. 2013, 16, 382-396. [CrossRef]

20. Khiari, Z.; Makris, D.P.; Kefalas, P. An investigation on the recovery of antioxidant phenolics from onion solid wastes employing water/ethanol-based solvent systems. Food Bioprocess Technol. 2009, 2, 337-343. [CrossRef]

21. Cuevas-Valenzuela, J.; González-Rojas, Á.; Wisniak, J.; Apelblat, A.; Pérez-Correa, J.R. Solubility of (+)-catechin in water and water-ethanol mixtures within the temperature range 277.6-331.2 K: Fundamental data to design polyphenol extraction processes. Fluid Phase Equilib. 2014, 382, 279-285. [CrossRef]

22. Cacace, J.; Mazza, G. Extraction of anthocyanins and other phenolics from black currants with sulfured water. J. Agric. Food Chem. 2002, 50, 5939-5946. [CrossRef] [PubMed]

23. Monrad, J.K.; Howard, L.R.; King, J.W.; Srinivas, K.; Mauromoustakos, A. Subcritical solvent extraction of anthocyanins from dried red grape pomace. J. Agric. Food Chem. 2010, 58, 2862-2868. [CrossRef] [PubMed]

24. Sant'Anna, V.; Marczak, L.D.F.; Tessaro, I.C. Kinetic modeling of anthocyanin extraction from grape marc. Food Bioprocess Technol. 2013, 6, 3473-3480. [CrossRef] 
25. González-Centeno, M.; Comas-Serra, F.; Femenia, A.; Rosselló, C.; Simal, S. Effect of power ultrasound application on aqueous extraction of phenolic compounds and antioxidant capacity from grape pomace (Vitis vinifera L.): Experimental kinetics and modeling. Ultrason. Sonochem. 2015, 22, 506-514. [CrossRef] [PubMed]

26. Khan, M.K.; Abert-Vian, M.; Fabiano-Tixier, A.-S.; Dangles, O.; Chemat, F. Ultrasound-assisted extraction of polyphenols (flavanone glycosides) from orange (Citrus sinensis L.) peel. Food Chem. 2010, 119, 851-858. [CrossRef]

27. Cacace, J.; Mazza, G. Optimization of extraction of anthocyanins from black currants with aqueous ethanol. J. Food Sci. 2003, 68, 240-248. [CrossRef]

28. Qu, W.; Pan, Z.; Ma, H. Extraction modeling and activities of antioxidants from pomegranate marc. J. Food Eng. 2010, 99, 16-23. [CrossRef]

29. Vilkhu, K.; Mawson, R.; Simons, L.; Bates, D. Applications and opportunities for ultrasound assisted extraction in the food industry-A review. Innov. Food Sci. Emerg. Technol. 2008, 9, 161-169. [CrossRef]

30. Vetal, M.D.; Lade, V.G.; Rathod, V.K. Extraction of ursolic acid from Ocimum sanctum by ultrasound: Process intensification and kinetic studies. Chem. Eng. Process. 2013, 69, 24-30. [CrossRef]

31. Pinelo, M.; Sineiro, J.; Núñez, M.A.J. Mass transfer during continuous solid-liquid extraction of antioxidants from grape byproducts. J. Food Eng. 2006, 77, 57-63. [CrossRef]

32. Amendola, D.; de Faveri, D.; Spigno, G. Grape marc phenolics: Extraction kinetics, quality and stability of extracts. J. Food Eng. 2010, 97, 384-392. [CrossRef]

33. Cacace, J.; Mazza, G. Mass transfer process during extraction of phenolic compounds from milled berries. J. Food Eng. 2003, 59, 379-389.

34. Shehata, E.; Grigorakis, S.; Loupassaki, S.; Makris, D.P. Extraction optimisation using water/glycerol for the efficient recovery of polyphenolic antioxidants from two Artemisia species. Sep. Purif. Technol. 2015, 149, 462-469. [CrossRef]

35. Karvela, E.; Makris, D.P.; Kalogeropoulos, N.; Karathanos, V.T. Deployment of response surface methodology to optimise recovery of grape (Vitis vinifera) stem polyphenols. Talanta 2009, 79, 1311-1321. [CrossRef] [PubMed]

(c) 2016 by the author; licensee MDPI, Basel, Switzerland. This article is an open access article distributed under the terms and conditions of the Creative Commons by Attribution (CC-BY) license (http://creativecommons.org/licenses/by/4.0/). 